\title{
Efficacy and safety of cinepazide maleate injection in patients with acute ischemic stroke: a multicenter, randomized, double- blind, placebo-controlled trial
}

Jun $\mathrm{Ni}^{1}$, Huisheng Chen ${ }^{2}$, Guofang Chen ${ }^{3}$, Yong Ji ${ }^{4}$, Fei $\mathrm{Yi}^{5}$, Zhuobo Zhang ${ }^{6}$, Yi Yang ${ }^{7}$, Jin $\mathrm{Wu}^{8}$, Xueli Cai ${ }^{9}$, Bei Shao ${ }^{10}$, Jianfeng Wang ${ }^{11}$, Yafang Liu ${ }^{12}$, Deqin Geng ${ }^{13}$, Xinhui Qu ${ }^{14}$, Xiaohong $\mathrm{Li}^{15}$, Yan Wei ${ }^{16}$, Jianping Ding ${ }^{17}$, Hua Lü ${ }^{18}$, Yining Huang ${ }^{19}$, Yonghua Huang ${ }^{20}$, Bo Xiao ${ }^{21}$, Tao Gong ${ }^{22}$, Liying Cui ${ }^{*}$ (D) and on behalf of the study collaboration group

\footnotetext{
Abstract

Background: Ischemic stroke is a leading cause of morbidity and mortality. Thrombolytic therapy improves disability and survival rates; however, to be effective, it must be given within $4.5 \mathrm{~h}$ of onset. Moreover, thrombolytic therapy is frequently contraindicated. Therefore, alternative therapeutic options are required. In China, cinepazide maleate injection has been shown to improve the cerebral collateral circulation and further reduce disability in stroke patients; however, very few studies investigating this therapy have been conducted to date. Therefore, this study aimed to further confirm the efficacy and safety of cinepazide maleate injection in patients with acute ischemic stroke.

Methods: Patients with acute ischemic stroke were administered an intravenous infusion of $320 \mathrm{mg}$ cinepazide maleate or placebo once daily for 14 days. All patients were also administered basic therapy (citicoline sodium). The primary efficacy endpoint was the proportion of patients with a modified Rankin scale $(m R S) \leq 2$ on day 90 . Secondary efficacy endpoints included Barthel Index $\geq 95$. Safety was evaluated by recording all adverse events (AEs), monitoring laboratory parameters and vital signs, and electrocardiogram.

\footnotetext{
* Correspondence: pumchcuily@sina.com

'Peking Union Medical College Hospital, Chinese Academy of Medical

Sciences, No.1 Shuaifuyuan Wangfujing Dongcheng District, Beijing 100730,

China

Full list of author information is available at the end of the article
}

(c) The Author(s). 2020 Open Access This article is licensed under a Creative Commons Attribution 4.0 International License, which permits use, sharing, adaptation, distribution and reproduction in any medium or format, as long as you give appropriate credit to the original author(s) and the source, provide a link to the Creative Commons licence, and indicate if changes were made. The images or other third party material in this article are included in the article's Creative Commons licence, unless indicated otherwise in a credit line to the material. If material is not included in the article's Creative Commons licence and your intended use is not permitted by statutory regulation or exceeds the permitted use, you will need to obtain permission directly from the copyright holder. To view a copy of this licence, visit http://creativecommons.org/licenses/by/4.0/ The Creative Commons Public Domain Dedication waiver (http://creativecommons.org/publicdomain/zero/1.0/) applies to the data made available in this article, unless otherwise stated in a credit line to the data. 
(Continued from previous page)

Results: In total, 937 patients with an acute ischemic stroke were included, with a mean (standard deviation, SD) National Institutes of Health Stroke Scale score of 8.8 (2.4) and a mean (SD) stroke onset of 30.9 (11.4) hours prior. Following treatment for 90 days, the proportion of patients with an mRS score $\leq 2$ was significantly higher in the cinepazide maleate group than in the control group $(60.9 \%$ vs. 50.1\%; $p=$ 0.0004). Moreover, the proportion of patients with a Barthel Index of $\geq 95$ on day 90 was also significantly higher in the cinepazide maleate group than in the control group (53.4\% vs. 46.7\%; $p=0.0230)$. There were no statistically significant differences in safety parameters between the cinepazide maleate and control groups.

Conclusions: The results of this study show that cinepazide maleate injection is superior to placebo in improving neurological function and activities of daily living, reducing disability, and promoting functional recovery in patients with acute ischemic stroke. Cinepazide maleate injection was safe and well tolerated with no unexpected AEs reported.

Trial registration: Chinese Clinical Trial Registry CTR20160292 and ChiCTR1900023827. Retrospectively registered June 13, 2019.

Keywords: Acute cerebral infarction, Cerebrovascular disease, Cinepazide maleate, Stroke

\section{Background}

Ischemic stroke is an acute cerebrovascular event caused by decreased blood flow to the brain. The long-term effects of stroke include decreased quality of life and a high rate of morbidity and mortality [1]. In recent years, ischemic stroke has been shown to be the leading cause of death in China, which has the highest stroke incidence $(247 / 100,000)$ and stroke mortality $(115 / 100,000)$ rates in the world [2]. The most common stroke subtype in China is ischemic stroke, which accounts for $69.6 \%$ of all stroke events [2].

Ischemic stroke is categorized into five subtypes based on etiology, as defined in the Trial of Org 10, 172 in Acute Stroke Treatment (TOAST) classification: large-artery atherosclerosis; cardioembolism; small-vessel occlusion; stroke of other determined etiology; and stroke of undetermined etiology [3]. Stroke etiology has a major influence on prognosis; therefore, the correct treatment strategy requires a rapid assessment followed by early diagnosis and intervention with a thrombolytic agent to minimize functional disability caused by nerve damage [4]. Thrombolytic therapy after acute ischemic stroke reduces morbidity and mortality rates and improves the quality of life of patients, but only if the patient is correctly diagnosed within $4.5 \mathrm{~h}$ of onset [5]. However, many patients are not diagnosed within this time frame, and even among those who are, many are contraindicated for thrombolytic therapy [6]. Therefore, other effective therapeutic options are required.

Cinepazide maleate is a piperazine derivative that acts as a weak calcium channel blocker and has been shown to reduce disability following acute ischemic stroke [7]. Cinepazide maleate potentiates the effects of increased endogenous adenosine in atrial tissues, retards the degradation of adenosine, inhibits platelet aggregation, reduces blood viscosity, and improves blood rheology [7-11]. A tablet formulation of cinepazide maleate was originally approved in 1974 but was withdrawn in the 1990 s owing to an apparent increased risk of agranulocytosis. A cinepazide maleate injection was later (in 2002) approved in China, where it is widely used for the treatment of acute ischemic stroke, the sequelae of brain trauma, unstable angina, and other cerebrovascular diseases [12-15]. Given the lack of good quality data on the efficacy of cinepazide maleate injection for treating ischemic stroke, the high incidence of ischemic stroke (and high mortality owing to ischemic stroke) in China, and the continued widespread use of cinepazide maleate injection in China, the present study was designed to evaluate and further confirm the efficacy and safety of cinepazide maleate injection for the treatment of patients after acute ischemic stroke.

\section{Methods}

\section{Study design and treatment}

This multicenter, randomized, double-blind, parallelgroup, placebo-controlled, post-market clinical trial aimed to evaluate the safety and efficacy of cinepazide maleate injection in Chinese patients with acute ischemic stroke (Fig. 1). This study was conducted across 72 medical centers (of which 65 enrolled patients and 60 treated patients with cinepazide maleate; five centers had only patients randomly assigned no drug treatment) in China from August 2016 to February 2019 and was registered in the Chinese Clinical Trial Registry (registration numbers: CTR20160292 and ChiCTR1900023827). The ethics 


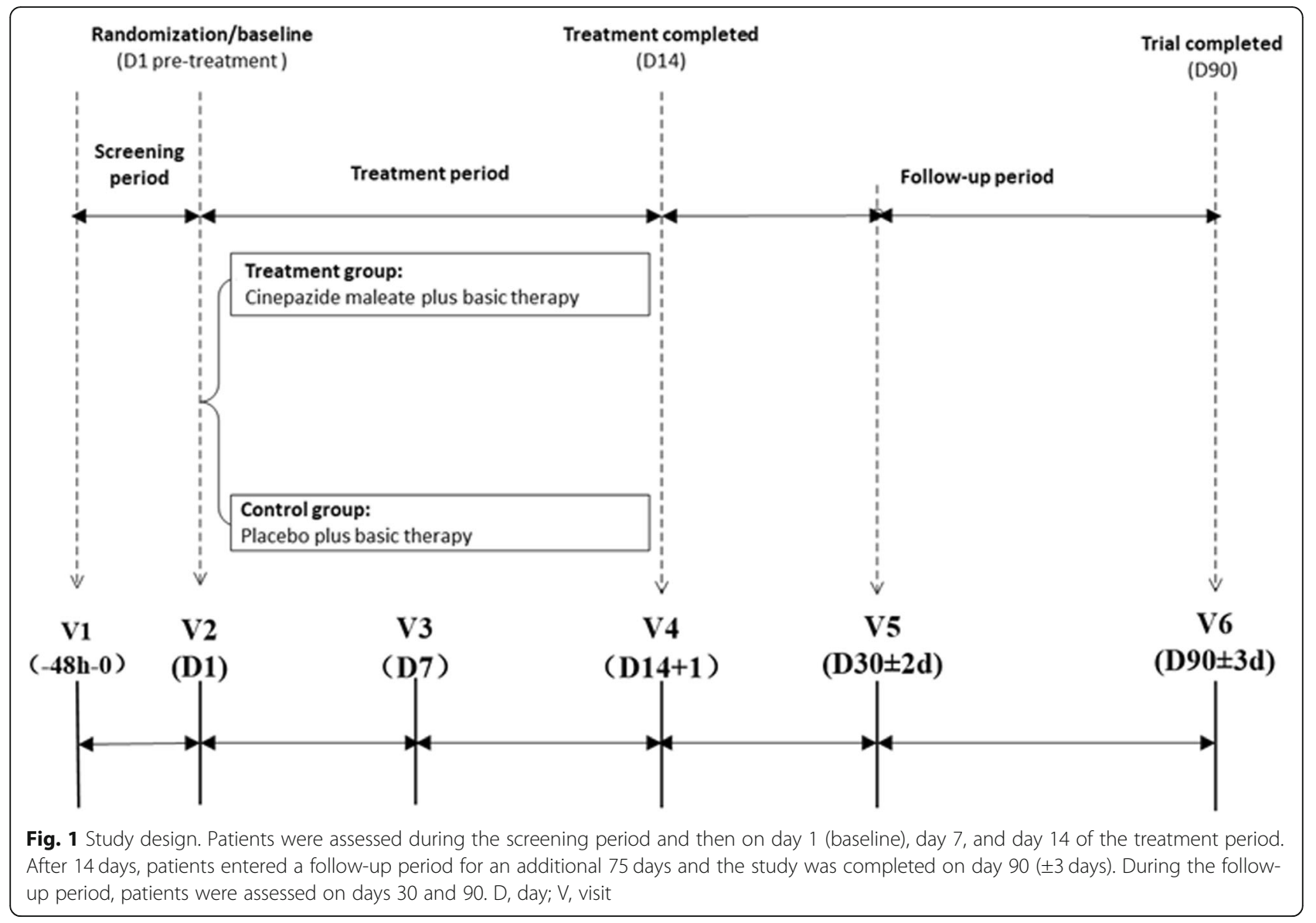

committees of all 72 research institutes reviewed and approved the study protocol. The study was conducted in accordance with the ethical guidelines for human medical research as stated in the Declaration of Helsinki (2013) and the ethical principles of the Chinese Good Clinical Practice for Drug Administration. All patients provided voluntary written informed consent prior to commencing any study procedures.

Patients received a continuous intravenous infusion of $320 \mathrm{mg}$ of cinepazide maleate (in $500 \mathrm{~mL}$ of saline) or placebo (saline alone) at a rate of $100 \mathrm{~mL} /$ hour once daily for 14 days. Patients also received basic therapy, consisting of an intravenous infusion of 250 $\mathrm{mL}$ of citicoline sodium $(0.5 \mathrm{~g}$ dissolved in $5 \%$ glucose or saline) once daily for 10 days. Furthermore, in accordance with the Chinese Guidelines on the Diagnosis and Treatment of Acute Ischemic Stroke in 2014 [16], all patients were allowed to receive antihypertensive, antihyperlipidemic, and anticoagulant agents together with agents to lower blood sugar and mannitol to reduce intracranial pressure.
Patients were assessed during the screening period and then on day 1 (baseline), day 7, and day 14 of the treatment period. After 14 days, patients entered a follow-up period for an additional 75 days and the study was completed on day 90 ( \pm 3 days). During the follow-up period, patients were assessed on day 30 and day 90 .

\section{Randomization and blinding}

This study used an interactive web response system for randomization and both patients and investigators were blinded throughout the study.

\section{Patients}

Initially, this study included patients with National Institutes of Health Stroke Scale (NIHSS) scores of 5-25 at first diagnosis. However, the entry criteria were revised to patients with NIHSS scores of 7-25 for the following reasons. First, in February 2018, the Chinese Food and Drug Administration issued guidelines for clinical trials of therapeutic drugs for acute ischemic stroke in which they pointed out that baseline severity 
may influence the outcome of clinical trials; therefore, the inclusion criteria were revised to limit the population to patients with moderate neurological impairment at baseline. Thus, based on our definition of mild neurological impairment, patients whose symptoms were classified as NIHSS 1-6 were excluded because of their high self-recovery capacity. In addition, the TOAST trial [17] evaluated the outcomes of 1281 acute ischemic stroke patients, and the results suggested that those with NIHSS scores $\geq 16$ at baseline tended to have a poor prognosis and those with NIHSS scores $\leq 6$ at baseline tended to have better outcomes. Furthermore, during an interim reestimation of the required sample size for this study, it was shown that, of the 533 patients who completed the last visit, up to $87.6 \%$ ( $311 / 355$ patients) of those who had an NIHSS score between 5 and 6 at baseline had a modified Rankin scale (mRS) score of $\leq 2$ at day 90. This finding suggested that patients with baseline NIHSS scores between 5 and 6 have a strong selfrecovery capacity.

Finally, the International Conference on Harmonization E9 guideline and Food and Drug Administration Guidance for Industry recommend changing the design of longterm clinical studies if considered appropriate based on new information or increased medical knowledge $[18,19]$. Although patients with an NIHSS score of 5 or 6 were initially included in the patient population, these patients were then excluded from the current FAS analysis.

In this study, the patient population included those who had experienced an ischemic stroke within the previous $48 \mathrm{~h}$ prior to study entry. Inclusion criteria were age 18-80 years, diagnosed with either a firsttime acute internal carotid artery (anterior circulation) stroke or a recurrent stroke with a good prognosis (mRS score of $0-1$ ) before time of relapse, and an NIHSS score of 7-25.

Exclusion criteria were: among patients with recurrent stroke, an mRS score of $\geq 2$ before onset of the most recent stroke; a cranial computed tomography scan indicating an intracerebral hemorrhage (e.g., hemorrhagic stroke, epidural hematoma, intracerebral hematoma, intraventricular hemorrhage, and subarachnoid hemorrhage); cerebral infarction accompanied by disorders of consciousness, transient ischemic attack, cerebral arteritis, brain tumor(s), traumatic brain injury, intracranial infection, or brain parasites; poorly controlled hypertension (systolic blood pressure $\geq 200 \mathrm{mmHg}$ or diastolic blood pressure $\geq 110$ $\mathrm{mmHg}$ ); high risk of cardiac embolism, acute myocardial infarction, or heart failure; bleeding tendency or a history of severe bleeding within the past 3 months; epilepsy; malignant tumor or a severe and progressive disease; and presence of a psychiatric disorder that may lead to poor compliance.

The following treatments were prohibited during the study: any interventional therapy, including thrombolytic therapy; fibrinogen-depleting therapy; platelet inhibitors except for aspirin and clopidogrel; cerebral vasodilators (e.g., cinnarizine, flunarizine, nicardipine, nimodipine); neuroprotective agents (e.g., edaravone, piracetam, monosialoganglioside sodium); drugs that improve cerebral circulation; or any traditional Chinese medicines with the indication of promoting blood circulation, removing blood stasis, or with the indication of treating cerebral infarction.

\section{Outcomes}

The primary efficacy endpoint was the percentage of patients with an mRS score of $\leq 2$ on day 90 . Secondary efficacy endpoints included the percentage of patients with a Barthel Index score of $\geq 95$ on days 14, 30, and 90; we report data for day 90 only here.

Safety was evaluated by monitoring adverse events (AEs), monitoring laboratory parameters (routine blood test, urine test, biochemical examinations, coagulation profile, and lipid profile) and vital signs, and electrocardiogram (parameters analyzed were heart rate, PR interval, QTc, and QRS intervals).

\section{Statistical analysis}

The sample size calculation was based on the estimated number of patients that would achieve a 90-day mRS score of $\leq 2$ points. Based on a previous study [20] and observations from clinical practice, we estimated the number of patients that would achieve a 90-day mRS score of $\leq 2$ points in the experimental and placebo groups to be 45 and $35 \%$, respectively. Thus, it was calculated that a sample size of 596 patients in each group would ensure an $80 \%$ power to detect differences between groups at a two-sided significance level of 0.05 . To allow for the exclusion of patients who had joined the trial with NIHSS scores of 5 and 6 at baseline (revision to inclusion criteria after the study commenced), and for the loss of patients during the study owing to withdrawal, the sample size required was estimated to be 1300 patients.

Patients who had an NIHSS score $\geq 7$ at the time of screening and were subsequently randomized for treatment were included in the full analysis set. To be included in the safety analysis set, patients were required to have received treatment after randomization.

Descriptive statistics were used to summarize patient demographics and clinical characteristics at baseline. A logistic regression analysis was used to determine the difference in efficacy endpoints between the groups, and a $p$-value of $<0.05$ was considered to show a statistically 
significant difference. Odds ratios (OR) were obtained using a logistic regression model with the treatment regimen, baseline NIHSS score, and onset time as covariates. An OR of $<1$ indicated a reduced risk. Changes from one mRS point category to another were assessed using independent sample rank sum tests. A p-value of $<0.05$ was considered to show a statistically significant difference.

The statistical software used was SAS version 9.4 (SAS Institute Inc. Cary, NC, USA).

\section{Results}

\section{Patients}

In this study, a total of 1366 patients were screened, of which 1301 patients were randomized to either the cinepazide maleate group $(n=650)$ or the control group $(n=651)$ (Fig. 2). Of these, 937 patients with an NIHSS score of 7-25 were included in the full analysis set (cinepazide maleate group, $n=466$; control group, $n=$ 471), and 1291 patients were included in the safety analysis set (cinepazide maleate group, $n=643$; control group, $n=648$ ).

Baseline characteristics and key clinical characteristics of patients included in this study are shown in Table 1; generally, these were well balanced between groups. In brief, the mean (standard deviation, SD) onset of cerebral infarction was 30.9 (11.4) hours prior to receiving the first study drug. Patients were recorded as having an mRS score at baseline of 0 $(0.0 \%), 1(0.1 \%), 2(1.4 \%), 3(31.7 \%), 4(62.1 \%)$, or 5 $(4.7 \%)$. In this study, $66.3 \%$ of patients were male and the mean (SD) body mass index was $24.3(3.3) \mathrm{kg} / \mathrm{m}^{2}$. The mean (SD) age was $61.2(10.0)$ years. There was a statistically significant difference in age between the cinepazide maleate group (60.3 [10.31]) and the placebo group (62.1 [9.65]); thus, we also performed

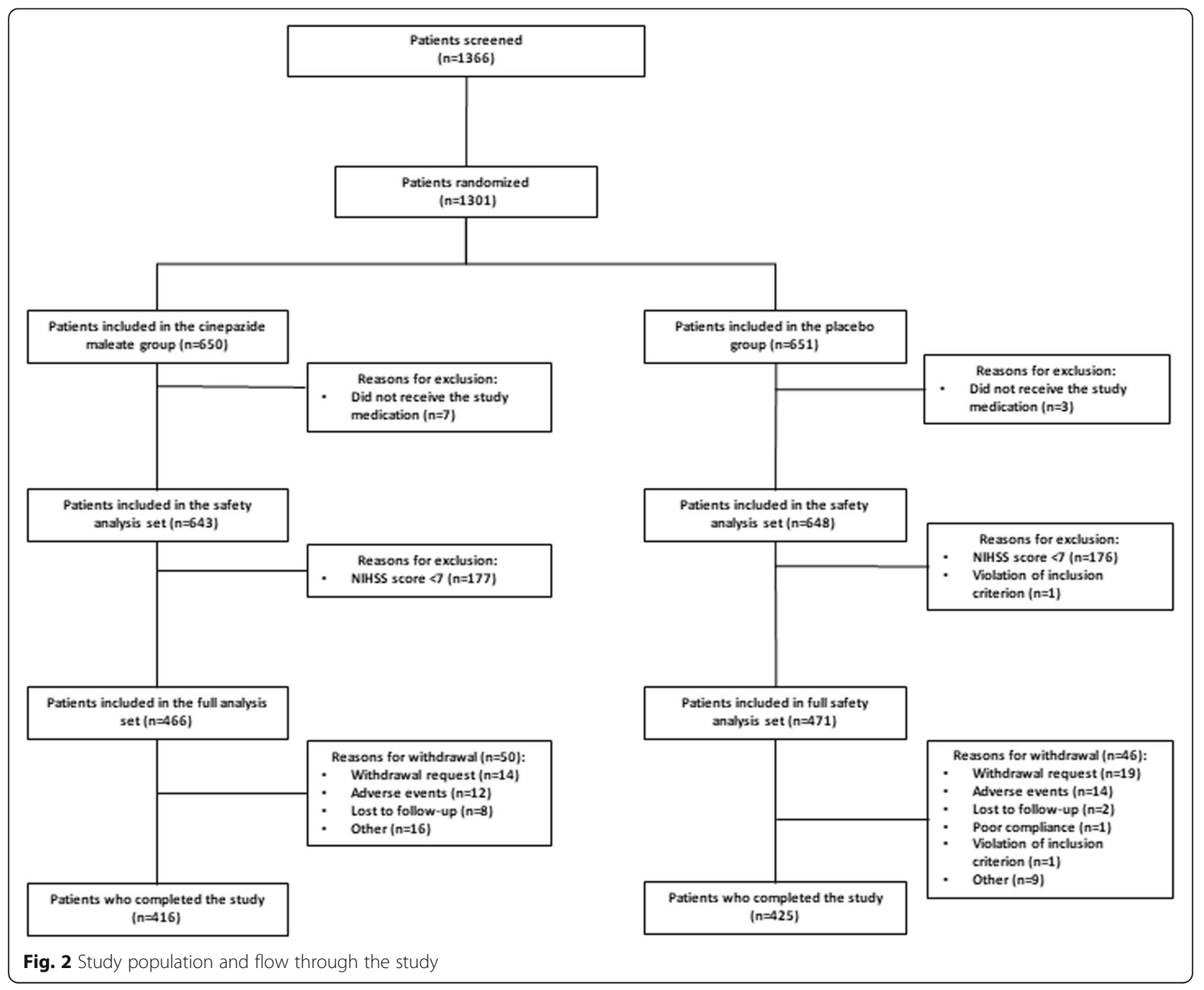


Table 1 Baseline characteristics of patients

\begin{tabular}{|c|c|c|c|}
\hline & Cinepazide maleate $(n=466)$ & Placebo $(n=471)$ & Total $(n=937)$ \\
\hline Age, years, mean (SD) & $60.3(10.31)$ & $62.1(9.65)$ & $61.2(10.02)$ \\
\hline \multicolumn{4}{|l|}{ Sex, n (\%) } \\
\hline Male & $312(67.0)$ & $309(65.6)$ & $621(66.3)$ \\
\hline Female & $154(33.1)$ & $162(34.4)$ & $316(33.7)$ \\
\hline \multicolumn{4}{|l|}{ Ethnicity, n (\%) } \\
\hline Han & $443(95.1)$ & $443(94.1)$ & $886(94.6)$ \\
\hline Others & $23(4.9)$ & $28(5.9)$ & $51(5.4)$ \\
\hline $\mathrm{BMl}, \mathrm{kg} / \mathrm{m}^{2}$, mean (SD) & $24.4(3.38)$ & $24.2(3.30)$ & $24.3(3.34)$ \\
\hline \multicolumn{4}{|l|}{ Onset of therapy, n (\%) } \\
\hline$<12 \mathrm{~h}$ & $24(5.2)$ & $30(6.4)$ & $54(5.8)$ \\
\hline $12-24 \mathrm{~h}$ & $122(26.2)$ & $119(25.3)$ & $241(25.7)$ \\
\hline $25-48 h$ & $316(67.8)$ & $319(67.7)$ & $635(67.8)$ \\
\hline$>48 \mathrm{~h}$ & $4(0.9)$ & $3(0.6)$ & $7(0.8)$ \\
\hline NIHSS score, median (Q1, Q3) & $8(7,10)$ & $8(7,10)$ & $8(7,10)$ \\
\hline \multicolumn{4}{|l|}{ mRS level, n (\%) } \\
\hline Level 0 & $0(0.0)$ & $0(0.0)$ & $0(0.0)$ \\
\hline Level 1 & $0(0.0)$ & $1(0.2)$ & $1(0.1)$ \\
\hline Level 2 & $7(1.5)$ & $6(1.3)$ & $13(1.4)$ \\
\hline Level 3 & $136(29.2)$ & $161(34.2)$ & $297(31.7)$ \\
\hline Level 4 & $303(65.0)$ & $279(59.2)$ & $582(62.1)$ \\
\hline Level 5 & $20(4.3)$ & $24(5.1)$ & $44(4.7)$ \\
\hline Prior history of stroke, n (\%) & $141(30.3)$ & $136(28.9)$ & $277(29.6)$ \\
\hline \multicolumn{4}{|l|}{ Comorbid disorders, n (\%) } \\
\hline Hypertension & $348(74.7)$ & $343(72.8)$ & $691(73.8)$ \\
\hline Hyperlipidemia & $161(34.6)$ & $156(33.1)$ & $317(33.8)$ \\
\hline Diabetes & $145(31.1)$ & $160(34.0)$ & $305(32.6)$ \\
\hline Carotid atherosclerosis & $105(22.5)$ & $128(27.2)$ & $233(24.9)$ \\
\hline Cerebral infarction & $110(23.6)$ & $107(22.7)$ & $217(23.2)$ \\
\hline Cerebral artery stenosis & $90(19.3)$ & 79 (16.8) & $169(18.0)$ \\
\hline Cerebral arteriosclerosis & $83(17.8)$ & $82(17.4)$ & $165(17.6)$ \\
\hline Carotid thrombosis & $82(17.6)$ & $69(14.7)$ & $151(16.1)$ \\
\hline Arteriosclerosis & $65(14.0)$ & $80(17.0)$ & $145(15.5)$ \\
\hline Hyperhomocysteinemia & $65(14.0)$ & $71(15.1)$ & $136(14.5)$ \\
\hline Hepatic steatosis & $60(12.9)$ & $63(13.4)$ & $123(13.1)$ \\
\hline Dyslipidemia & $46(9.9)$ & $53(11.3)$ & 99 (10.6) \\
\hline Coronary artery disease & $51(10.9)$ & $43(9.1)$ & $94(10.0)$ \\
\hline
\end{tabular}

Onset of therapy, time from onset to first dose

$B M I$ body mass index, $m R S$ modified Rankin scale, NIHSS National Institutes of Health Stroke Scale, SD standard deviation

analyses after making an adjustment to endpoint values based on this difference. Baseline NIHSS scores were 7-9 points in 694 subjects, $10-14$ points in 212 subjects, $15-10$ points in 28 subjects, and 20-25 points in three subjects. Furthermore, $94.6 \%$ of patients were classified as Han Chinese.

\section{Primary outcome}

There was a significant difference between the cinepazide maleate group and the control group in the proportion of patients in the full analysis set with an mRS score $\leq 2$ on day $90(60.9 \%$ vs. $50.1 \%, p=0.0004 ; p=$ 0.001 when data were further adjusted for age) (Table 2). 
Table 2 Distribution of mRS scores on day 90 after treatment (full analysis set)

\begin{tabular}{|c|c|c|c|c|}
\hline & $\begin{array}{l}\text { Cinepazide maleate } \\
(n=466)\end{array}$ & $\begin{array}{l}\text { Placebo } \\
(n=471)\end{array}$ & $P$ & Z \\
\hline mRS score at 90 days & & & 0.009 & -2.595 \\
\hline Level 0 & $67(14.4)$ & $69(14.7)$ & - & - \\
\hline Level 1 & $139(29.8)$ & $107(22.7)$ & - & - \\
\hline Level 2 & $78(16.7)$ & $60(12.7)$ & - & - \\
\hline Level 3 & $91(19.5)$ & $139(29.5)$ & - & - \\
\hline Level 4 & $39(8.4)$ & $43(9.1)$ & - & - \\
\hline Level 5 & $2(0.4)$ & $7(1.5)$ & - & - \\
\hline$\leq$ level 2 & $284(60.9)$ & $236(50.1)$ & 0.0004 & $0.607(0.460,0.801)^{\mathrm{a}}$ \\
\hline Missing (did not complete the study) & $50(10.7)$ & $46(9.8)$ & & \\
\hline
\end{tabular}

Data are presented as $\mathrm{n}(\%)$

$\mathrm{Cl}$ confidence interval, $m R S$ modified Rankin scale, $Z \mathrm{Z}$ statistic

$p$ value and $Z$ statistic are from two independent sample rank sum tests

${ }^{a}$ Odds ratio ( $95 \%$ confidence interval)

Compared with the control group, the odds ratio for a patient in the cinepazide maleate group having an $\mathrm{mRS}$ score $>2$ on day 90 was 0.607 ( $95 \%$ confidence interval [CI]: $0.460,0.801)$. This difference was maintained after adjusting for possible center effects as well as baseline NIHSS score and time from onset to administration of treatment in a sensitivity analysis, with an effective percent difference of $10.76 \%$ (standard error, 3.155\%; 95\% CI 4.57-16.94) in favor of cinepazide maleate. In addition, the overall distribution of mRS scores on day 90 showed a significant effect that favored the administration of cinepazide maleate injection over placebo $(p=0.009)$ (Table 2; Fig. 3).

\section{Secondary outcome}

The proportion of patients with a Barthel Index of $\geq 95$ on day 90 was significantly higher in the cinepazide maleate group than in the control group $(53.4 \%$ vs. $46.7 \%, p=0.0230 ; p=0.012$ when data were further adjusted for age). As such, when compared with the control group, patients in the cinepazide maleate group had

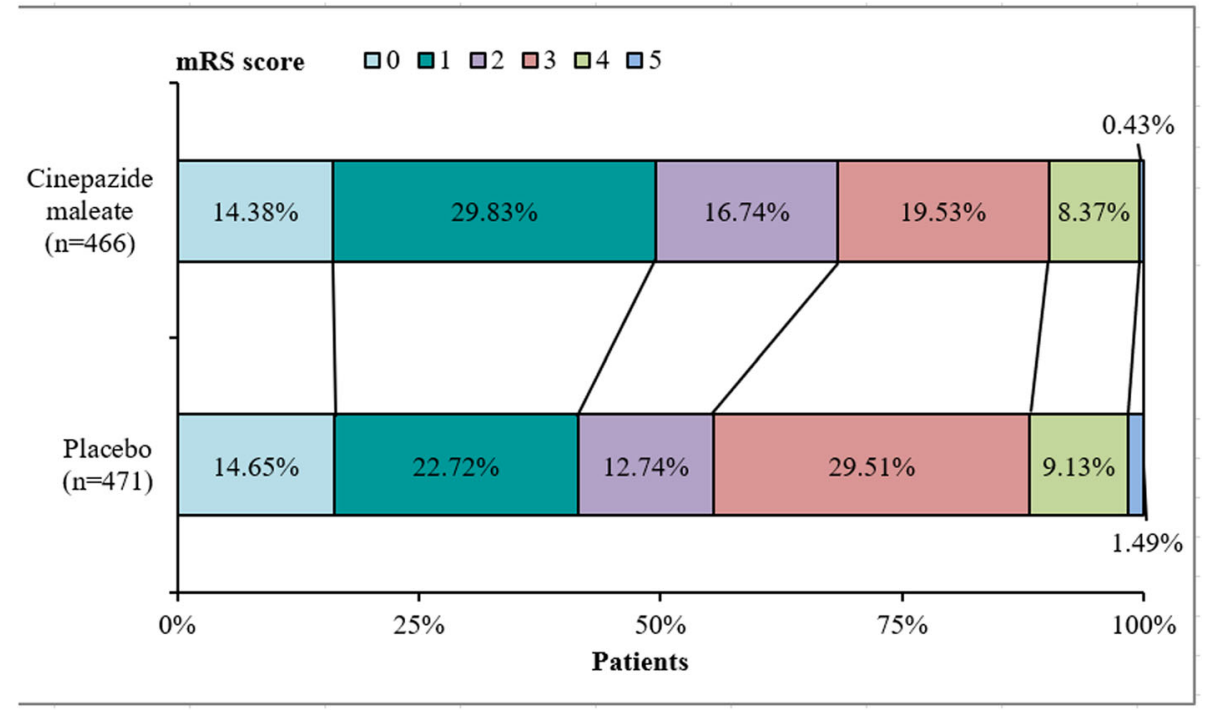

Fig. 3 Distribution of mRS scores on day 90 among patients in the full analysis set. Proportion of patients in each mRS score category (0 to 5) by treatment group. mRS, modified Rankin Scale 
a lower risk of a Barthel Index $<95$ on day $90(\mathrm{OR}=$ 0.719; 95\% CI: 0.542, 0.956).

\section{Adverse events}

In the cinepazide maleate and control groups, respectively, 82.0 and $84.1 \%$ of patients reported an $\mathrm{AE}$ (Table 3). The most common AE reported in the cinepazide maleate and control groups was constipation (26.0 and $26.5 \%$, respectively), with no statistical difference $(p=0.82)$. The incidence of hypokalemia differed significantly between the groups, being $6.1 \%$ in the cinepazide maleate group and $10.5 \%$ in the control group ( $p=$ 0.0004), but this difference was not thought to be related to the investigational product. AEs occurring with an incidence $\geq 5 \%$ are listed in Table 3 . Other than hypokalemia, none of these differed significantly between the two groups.

There were no clinically significant changes in vital signs and most clinical laboratory parameters between groups (Supplementary file). In a small number of patients there were changes in blood, urinary, and blood biochemistry parameters; however, these were associated with the underlying disease or were recorded as an AE. There were no clinically significant changes in electrocardiogram measurements for both groups. In total, there were 23 deaths in the study (cinepazide maleate group, $n=10$; control group, $n=13$ ), of which none were attributed to the study drug. Eighteen deaths were related to multiple organ dysfunctional syndrome, cerebral hernia, and acute myocardial

Table 3 Safety profile summary and most common (frequency $\geq 5 \%$ ) adverse events (safety analysis set)

\begin{tabular}{|c|c|c|c|c|}
\hline & $\begin{array}{l}\text { Cinepazide maleate } \\
(n=643)\end{array}$ & $\begin{array}{l}\text { Placebo } \\
(n=648)\end{array}$ & $\begin{array}{l}\text { Total } \\
(n=1291)\end{array}$ & $\begin{array}{l}P \text { value for the comparison } \\
\text { between groups }\end{array}$ \\
\hline All adverse events & $527(82.0)$ & $545(84.1)$ & $1072(83.0)$ & 0.30 \\
\hline Drug-related adverse events & $61(9.5)$ & $79(12.2)$ & $140(10.8)$ & 0.12 \\
\hline Serious adverse events & $62(9.6)$ & $74(11.4)$ & $136(10.5)$ & 0.30 \\
\hline Drug-related serious adverse events & $2(0.3)$ & $1(0.2)$ & $3(0.2)$ & 0.99 \\
\hline Adverse events leading to discontinuation & $11(1.7)$ & $15(2.3)$ & $26(2.0)$ & 0.44 \\
\hline Adverse events leading to death & $10(1.6)$ & $13(2.0)$ & $23(1.8)$ & 0.54 \\
\hline Adverse events occurring with a frequency $\geq 5 \%$ (total) & $345(53.7)$ & $365(56.3)$ & $710(55.0)$ & 0.33 \\
\hline Gastrointestinal diseases & $167(26.0)$ & $172(26.5)$ & $339(26.3)$ & 0.82 \\
\hline Constipation & $167(26.0)$ & $172(26.5)$ & $339(26.3)$ & 0.82 \\
\hline Infectious diseases & 85 (13.2) & $97(15.0)$ & $182(14.1)$ & 0.37 \\
\hline Upper respiratory tract infection & $29(4.5)$ & $42(6.5)$ & $71(5.5)$ & 0.12 \\
\hline Urinary tract infection & $31(4.8)$ & $37(5.7)$ & $68(5.3)$ & 0.47 \\
\hline Pulmonary infection & $30(4.7)$ & $36(5.6)$ & $66(5.1)$ & 0.47 \\
\hline Metabolic and nutritional diseases & $66(10.3)$ & $93(14.4)$ & $159(12.3)$ & 0.025 \\
\hline Hypokalemia & $39(6.1)$ & $68(10.5)$ & $107(8.3)$ & 0.004 \\
\hline Hypoproteinemia & $35(5.4)$ & $40(6.2)$ & $75(5.8)$ & 0.58 \\
\hline Nervous system disorders & $64(10.0)$ & $76(11.7)$ & $140(10.8)$ & 0.31 \\
\hline Headache & $40(6.2)$ & $46(7.1)$ & $86(6.7)$ & 0.53 \\
\hline Dizziness & $36(5.6)$ & $37(5.7)$ & $73(5.7)$ & 0.93 \\
\hline Hepatobiliary diseases & $52(8.1)$ & $61(9.4)$ & $113(8.8)$ & 0.4 \\
\hline Liver function abnormalities & $52(8.1)$ & $61(9.4)$ & $113(8.8)$ & 0.4 \\
\hline Cardiovascular disorders & $51(7.9)$ & $42(6.5)$ & $93(7.2)$ & 0.31 \\
\hline Increased blood pressure & $51(7.9)$ & $42(6.5)$ & $93(7.2)$ & 0.31 \\
\hline Psychiatric disorders & $39(6.1)$ & $34(5.3)$ & $73(5.7)$ & 0.52 \\
\hline Insomnia & $39(6.1)$ & $34(5.3)$ & $73(5.7)$ & 0.52 \\
\hline Respiratory, chest and mediastinal diseases & $29(4.5)$ & $37(5.7)$ & $66(5.1)$ & 0.33 \\
\hline Cough & $29(4.5)$ & $37(5.7)$ & $66(5.1)$ & 0.33 \\
\hline
\end{tabular}

Data are presented as $\mathrm{n}(\%)$

Increased blood pressure was defined as a systolic blood pressure of $120-139 \mathrm{mmHg}$ or a diastolic blood pressure of $80-89 \mathrm{mmHg}$ 
infarction with the remaining five deaths of unknown cause.

\section{Discussion}

This was a large-scale, multicenter, randomized, double-blind, placebo-controlled study that aimed to validate cinepazide maleate injection for the treatment of acute ischemic stroke in China. The results showed that, compared with placebo, a significantly higher proportion of patients treated with cinepazide maleate achieved an mRS score $\leq 2$ and Barthel Index $\geq 95$ at day 90 , indicating that cinepazide maleate promotes post-stroke functional recovery and improves long-term activities of daily living (ADL) score compared with standard treatment.

During ischemia, adenosine is released in large quantities [21]. This is thought to ameliorate brain injury by reducing $\mathrm{Ca}^{2+}$ influx and lowering the presynaptic release of the excitotoxic neurotransmitter glutamate [21-23]. Adenosine and its receptors are attractive therapeutic targets for the treatment of stroke, although many selective $A_{1}$ agonists cause sedation, bradycardia, and hypotension [24]. As a potentiator of adenosine A2 receptors, cinepazide maleate not only selectively potentiates the relaxing response of adenosine, it also prevents adenosine degradation and increases vasodilation via its effects on vascular endothelial function, and thus potentially reduces disability after stroke $[10,25,26]$.

The efficacy of cinepazide maleate in the treatment of patients with acute carotid cerebral infarction has previously been reported in several randomized controlled trials [13-15]. For example, in a study by Liu et al., treatment with cinepazide maleate within $24 \mathrm{~h}$ significantly improved cerebral blood flow $(p<0.05)$ and the Barthel Index $(p<0.05)$ in patients with craniocerebral trauma compared with standard treatment [13]. In addition, Zhang et al. showed that, in patients treated with cinepazide maleate within $12 \mathrm{~h}$ of an acute carotid stroke, there was a significant improvement in the combined primary outcome (mRS level 0-2, Barthel Index $\geq 75$, NIHSS score 01 , and an NIHSS score that had dropped by $>8$ points from baseline) on day 90 compared with standard treatment alone $(p=0.047)$ [14]. The mRS and Barthel Index assess global disability and ADL (including self-care and mobility), respectively, and both can be used to predict a patient's independence [27]. In this study, the proportion of patients with an $\mathrm{mRS} \leq 2$ or a Barthel Index of $\geq 95$ on day 90 were higher after cinepazide maleate treatment compared with standard treatment. These data are similar to those from previous clinical trials; therefore, it was concluded that cinepazide maleate injection improves neurological function, thus reducing disability and promoting functional recovery.

Overall, the safety profile of cinepazide maleate administration was similar to what has previously been reported in the literature [28-31]. Cinepazide maleate therapy has also previously been associated with AEs related to the blood system (e.g., leukopenia and neutropenia) [28]. The incidence of leukopenia was $0.4 \%$ in one study [29] and $0.2 \%$ in another [31]. In both studies there were no cases of agranulocytosis reported. In the present study, decreased white blood cells was only reported as an $\mathrm{AE}$ in four patients $(0.6 \%)$ and three patients $(0.5 \%)$ in the cinepazide maleate and control groups, respectively. Of these, only one case in the cinepazide maleate group was reported as a drug-related $\mathrm{AE}$, and this was subsequently resolved without treatment. Leukopenia was only reported in one patient $(0.2 \%)$ in the cinepazide maleate group, consistent with previous reports; however, this case was not considered related to cinepazide maleate therapy. Therefore, our data indicate that cinepazide maleate is well tolerated and has a safety profile similar to that reported previously.

The main limitation of this study is the lack of generalizability to other populations because the sample comprised only Chinese patients who had experienced a cerebral infarction caused by an acute internal carotid artery stroke. As such, patients who experienced an acute stroke that produced a disorder of consciousness were excluded. However, it is standard practice to exclude subjects with minor stroke from trials of stroke therapy owing to their high selfrecovery capacity [32], and the threshold for minor stroke was set slightly higher in the present study than in overseas studies based on Chinese Food and Drug Administration guidelines. Thus, the findings are potentially very relevant for Chinese stroke patients outside of China and may support a need for regulatory applications and further trials in other countries. In addition, for a post-marketing confirmatory study, the follow-up period was relatively short; therefore, future studies are required to investigate the effect of cinepazide maleate injection on longterm recovery, although the results to 90 days are encouraging.

\section{Conclusions}

The results of this study confirm that cinepazide maleate injection is safe and effective for the treatment of patients following acute ischemic stroke. Overall, cinepazide maleate injection was well tolerated with no novel safety issues reported. 


\section{Appendix}

Table 4 The following ethics committees (including institutions that did not enroll patients) approved the study protocol: Reference numbers for each approval are provided

\begin{tabular}{|c|c|c|}
\hline \# & Ethics committee name & Reference number \\
\hline 1 & Ethics Committee of Peking Union Medical College Hospital & KS2018077 \\
\hline 2 & Institutional Review Board of Chinese PLA General Hospital & C2016-023-05 \\
\hline 3 & Ethics Committee of Army General Hospital of PLA & BZEC2016-YW-001-03 \\
\hline 4 & Ethics Committee of Beijing Hospital & 2016BJYYEC-105-05 \\
\hline 5 & Peking University Third Hospital Medical Science Research Ethics Committee & 2017-007-04 \\
\hline 6 & Biomedical Research Ethics Committee of Peking University First Hospital & 2016-07 \\
\hline 7 & Ethics Committee of Naval General Hospital & HZYW-YJ-2016-7-2 \\
\hline 8 & China Rehabilitation Research Center Medical Ethics Committee & $2017-008$ \\
\hline 10 & Tianjin Huanhu Hospital Medical Ethics Committee & $2018-7$ \\
\hline 11 & Ethical Committee of The Second Hospital of Hebei Medical University & 2015R001846 \\
\hline 12 & Ethics Committee of Harrison International Peace Hospital & 2016-03-08 \\
\hline 13 & Ethics Committee of Jinan Central Hospital & $\mathrm{AF} / \mathrm{SC}-02 / 02.0$ \\
\hline 16 & IRB of Shuguang Hospital affiliated with Shanghai University of TCM & $2016-491-42$ \\
\hline 17 & Ethics Committee of the Affiliated Hospital of Xuzhou Medical College & XYFY2016-YL016-15 \\
\hline 18 & Ethics Committee of the Second Affiliated Hospital of Nanjing Medical University & 2016-YW-008-LP-01 \\
\hline 19 & Medical Ethics Committee of Zhejiang Hospital & $2016-15 G-X 3$ \\
\hline 20 & Ethics Committee of Affiliated Hospital of Hangzhou Normal University & 2018-00000037 \\
\hline 21 & Ethics Committee of Sir Run Run Shaw Hospital of Zhejiang University School of Medicine & $20,170,809-5$ \\
\hline 22 & Ethics Committee of First Affiliated Hospital of Wenzhou Medical College & 2018-058 \\
\hline 23 & Ethical Committee of The Jiangxi Provincial. People's Hospital & 2018-11 \\
\hline 24 & Ethics Committee of the Third Affiliated Hospital of Nanchang University & $2016-001$ \\
\hline 26 & YiChang Central People's Hospital Medical Ethics Committee & 2016-005-11 \\
\hline 27 & Ethics Committee of Huangshi Central Hospital & 2016-SJN-004 \\
\hline 28 & Ethics Committee of Xiangya Hospital Central South University & $201,708,085$ \\
\hline 29 & Ethics Committee of the Third Hospital of Changsha & 2016EC-006 \\
\hline 30 & Ethics Committee of First People's Hospital of Yueyang & 2016-006-2018-02 \\
\hline 31 & Ethic committee of the First Affiliated Hospital of Xiamen University & XMYY-2016Y016-05 \\
\hline 32 & Medical Ethics Committee of Zhongshan Hospital Affiliated to Xiamen University & XMZSIRB2018-017 \\
\hline 33 & Medical Ethics Committee of Sun Yat-Sen Memorial Hospital, Sun Yat-Sen University & 2019-03 \\
\hline 34 & Medical ethics committee branch of Dongguan People's Hospital & DRYA2016-008-B1 \\
\hline 35 & Ethics Committee of Liuzhou Worker's Hospital & 201,615-PL1 \\
\hline 36 & Ethical Committee of Hainan provincial people's Hospital & $2017-100$ \\
\hline 38 & Ethics Committee of the General Hospital of Shenyang Military Region of the Chinese People's Liberation Army & $2016-51-2$ \\
\hline 39 & Ethics Committee of the People's Hospital of Jilin Province & $2016-Y-016$ \\
\hline 40 & Ethics Committee of the Affiliated Hospital of Yanbian University & 2016-008-09 \\
\hline 41 & Ethics Committee of Inner Mongolia Baogang Hospital & 2016-BL-12 \\
\hline 42 & Ethics Committee of Inner Mongolia Autonomous Region People's Hospital & YWLCSYLL2016-014-06 \\
\hline 43 & Ethics Review Committee of Shaanxi Provincial People's Hospital & 2016Y004 \\
\hline 44 & Ethics Committee of Ningxia Medical University General Hospital & 2018-17 \\
\hline 47 & Ethics Committee of Xuan Wu Hospital of Capital Medical University & $2016-022-2$ \\
\hline 48 & The Second Hospital of Shanxi Medical University Ethics Committee & 2017-KS-087 \\
\hline 49 & Tianjin First Central Hospital Clinical Research Ethics Committee & 2019-010 \\
\hline
\end{tabular}


Table 4 The following ethics committees (including institutions that did not enroll patients) approved the study protocol: Reference numbers for each approval are provided (Continued)

\begin{tabular}{|c|c|c|}
\hline$\#$ & Ethics committee name & Reference number \\
\hline 50 & Ethics Committee of the First Hospital of Jilin University & $2018-161,123-224-1$ \\
\hline 51 & Ethics Committee of the Hunan Provincial People's Hospital & $2016-07.1$ \\
\hline 52 & Ethics Committee of the Second Affiliated Hospital of University of South China & $201,806-01-034$ \\
\hline 53 & Ethics Committee of Xuzhou Central Hospital & XZXY-LY-20180502-2,016,010 \\
\hline 55 & Ethics Committee of Pingxiang People's Hospital & 2016D010-F08 \\
\hline 56 & Ethics Committee of Affiliated Hospital of Nantong University & 2016-Y010-X02 \\
\hline 58 & Ethics Committee of The First Affiliated Hospital of Soochow University & $2017-061$ \\
\hline 59 & Ethics Committee of Baotou Central Hospital & $2018-13 \mathrm{H}$ \\
\hline 60 & Medical Ethics Committee of Lishui Municipal Central Hospital & 2017-02-03 \\
\hline 61 & Ethics Committee of the Affiliated Hospital of Chengde Medical College & 2018LL-K001 \\
\hline 62 & Ethics Committee of the second Hospital of Jilin University & $2017-006$ \\
\hline 63 & Ethics Committee of Jilin Neuropsychiatric Hospital & 2018--03 \\
\hline 65 & Ethics Committee of Meihekou City Central Hospital & 2017-SNK-001 \\
\hline 66 & Medical Ethics Committee of the Fourth Affiliated Hospital of Harbin Medical University & $2017-006$ \\
\hline 67 & Quzhou People's Hospital Ethics Committee & $2017-1-2$ \\
\hline 68 & Ethics Committee of Chenzhou First People's Hospital & $20,170,629$ \\
\hline 70 & Medical Ethics Committee of Peking University Shougang Hospital & IRB-2017-023-11 \\
\hline 71 & Ethics Committee of Taizhou People's Hospital & YW201700620 \\
\hline 72 & Ethics Committee of Huai'an Second People's Hospital & HEYL-P-2017-01-03 \\
\hline 73 & Ethic Committee of The Third Affiliated Hospital of Southern Medical University & 2017-08-2 \\
\hline 74 & Handan Center Hospital Research Ethics Committee & 2017-001-02 \\
\hline 75 & Ethics Committee of General Hospital of Xuzhou Mining Group & 2018-042301 \\
\hline 76 & Ethics Committee of Zhengzhou First People's Hospital & 2017-01-001 \\
\hline 77 & $\begin{array}{l}\text { Ethics Committee of Cangzhou Hospital of integrated Traditional Chinese and Western Medicine of Hebei } \\
\text { Province }\end{array}$ & $2,018,006$ \\
\hline 78 & Ethics Committee of the First Affiliated Hospital Of Henan University & $\begin{array}{l}\text { No reference number } \\
\text { available }\end{array}$ \\
\hline 79 & Ethics Committee of Luohe Central Hospital & IEC-C-008-A07-V1.1 \\
\hline 80 & Medical Ethics Committee of Dalian Municipal Central Hospital & 2017-013-02 \\
\hline 81 & Ethics Committee of Tonghua Municipal Central Hospital & 2018-03 \\
\hline
\end{tabular}

\section{Supplementary information}

Supplementary information accompanies this paper at https://doi.org/10 1186/s12883-020-01844-8.

Additional file 1: Supplementary Table. Laboratory results and vital signs for each group before and after treatment (safety set)

\section{Abbreviations}

AE: Adverse event; Cl: Confidence interval; mRS: modified Rankin scale; NIHSS: National Institutes of Health Stroke Scale; OR: Odds ratio; SD: Standard deviation

\section{Acknowledgments}

The authors would also like to acknowledge the contribution of all staff at each participating study center. The authors would also like to acknowledge Prof. Chuanqiang Pu from Chinese PLA General Hospital; Prof. Maolin He from Beijing Shijitan Hospital; Li Guo from The Second Hospital of Hebei Medical University; Jin Shi from Air Force General Hospital, PLA; Jielai Xia from The Fourth Military Medical University; Suodi Zhai from Peking University Third Hospital; Xiuli Zhao from Beijing Tongren Hospital; and Hua Bai from Peking Union Medical College Hospital for their contribution to the study design and for statistical analyses.

Study collaboration group:

Liying Cui, Peking Union Medical College Hospital, Chinese Academy of Medical Sciences, Beijing, China

Jun Ni, Peking Union Medical College Hospital, Chinese Academy of Medical Sciences, Beijing, China

Huisheng Chen, General Hospital of Northern Theater Command, Shenyang, China

Guofang Chen, Xuzhou Central Hospital, Xuzhou, China

Yong Ji, Tianjin Huanhu Hospital, Tianjin, China

Fei Yi, Pingxiang People's Hospital, Pingxiang, China

Zhuobo Zhang, Fourth Affiliated Hospital of Harbin Medical University, Harbin, China

Yi Yang, First Bethune Hospital of Jilin University, Changchun, China Jin Wu, Second Affiliated Hospital of Nanjing Medical University, Nanjing, China 
Xueli Cai, Lishui Municipal Central Hospital, Lishui, China

Bei Shao, First Affiliated Hospital of Wenzhou Medical University, Wenzhou,

China

Jianfeng Wang, Dalian Municipal Central Hospital, Dalian, China

Yafang Liu, Huangshi Central Hospital, Huangshi, China

Deqin Geng, Affiliated Hospital of Xuzhou Medical University, Xuzhou, China

Xinhui Qu, Jiangxi Provincial People's Hospital affiliated to Nanchang

University, Nanchang, China

Xiaohong Li, Jinan Central Hospital, Jinan, China

Yan Wei, Hengshui People's Hospital (Harrison International Peace Hospital), Hengshui, China

Jianping Ding, Xuan Wu Hospital, Capital Medical University, Beijing, China

Hua Lü, Shaanxi Provincial People's Hospital, Xi'an, China

Yining Huang, Peking University First Hospital, Beijing, China

Yonghua Huang, Seventh Medical Center of the Chinese PLA General

Hospital, Beijing, China

Bo Xiao, Xiangya Hospital Central South University, Changsha, China

Tao Gong, Beijing Hospital, Beijing, China

Dong Wang, Inner Mongolia Baogang Hospital, Baotou, China

Shugen Han, Meihekou Central Hospital, Meihekou, China

Xiaoping Gao, Hunan Provincial People's Hospital, Hunan, China

Xiaorong Zhuang, Zhongshan Hospital Affiliated to Xiamen University,

Xiamen, China

Guojun Tan, The Second Hospital of Hebei Medical University, Shijiazhuang,

China

Runxiu Zhu, Inner Mongolia People's Hospital, Baotou, China

Hongye Bi, Tianjin Union Medical Center, Nankai University Affiliated Hospital, Tianjin, China

Hong Yang, Liuzhou Workers' Hospital, Liuzhou, China

Youqing Deng, First Hospital of Nanchang, Nanchang, China

Jinghua Zhou, Yichang Central People's Hospital, Yichang, China

Shengzhe Zheng, Yanbian University Hospital, Yanji, China

Zhiyong Wang, Cangzhou Hospital of Integrated Traditional Chinese and

Western Medicine, Cangzhou, China

Xiaodong Lu, Affiliated Hospital of Hangzhou Normal University (Hangzhou

Second People's Hospital), Hangzhou, China

Juntao Li, Handan Central Hospital, Handan, China

Lina Huang, First Affiliated Hospital of Henan University of Science and

Technology, Luoyang, China

Weimin Hu, Second Hospital of Shanxi Medical University, Taiyuan, China

Dawei Zang, Tianjin First Central Hospital, Tianjin, China

Xiaoxi Yao, Chenzhou No. 1 People's Hospital, Chenzhou, China

Li Li, Jilin Province People's Hospital, Changchun, China

Liandong Zhao, The Second People's Hospital of Huai'an, Huai'an, China

Luoqing Li, The First People's Hospital of Yueyang, Yueyang, China

Shifang Wang, Dongguan People's Hospital, Dongguan, China

Kaifu Ke, Affiliated Hospital of Nantong University, Nantong, China

Tianming Lu, Third Affiliated Hospital of Southern Medical University,

Guangzhou, China

Qilin Ma, First Affiliated Hospital of Xiamen University, Xiamen, China

Qing Zhang, General Hospital of Ningxia Medical University, Yinchuan, China Baojun Wang, Baotou Central Hospital, Baotou, China

Liang Zhao, Affiliated Hospital of Chengde Medical College, Chengde, China

Hongliang Dong, Brain Hospital of Jilin Province, Changchun, China

Wei Gao, Peking University Shougang Hospital, Beijing, China

Ying Liu, Jiangsu Taizhou People's Hospital, Taizhou, China

Yamei Tang, Sun Yat-Sen Memorial Hospital, Sun Yat-Sen University,

Guangzhou, China

Junfeng Gao, Tonghua Central Hospital, Tonghua, China

Xiaofei Yu, Shanghai Shuguang Hospital, Shanghai, China

Libin Guo, Siping Hospital of China Medical University, Siping, China

Haiyan Lin, People's Hospital of Quzhou, Quzhou, China

Xiue Wei, General Hospital of Xuzhou Mining Group (The Second Affiliated

Hospital of Xuzhou Medical University), Xuzhou, China

Chenglin Tian, Chinese People's Liberation Army General Hospital, Beijing, China

Tong Zhang, China Rehabilitation Research Center, Beijing, China

Yaguo Li, Zhejiang Hospital, Hangzhou, China

Guoqiang Wen, Hainan General Hospital, Haikou, China

Chengfang Zhou, University of South China Second Hospital, Hengyang,

China
Qi Fang, First Affiliated Hospital of Soochow University, Suzhou, China

\section{Authors' contributions}

LC contributed to the study design and final approval of the manuscript. JN contributed to the study design and writing of the manuscript. All other authors (HC, GC, YJ, FY, ZZ, YY, J Wu, XC, BS, J Wang, $Y L, D G, X Q, X L, Y W, J D, H L$, Yining $H$, Yonghua $H, B X$, and $T G$ ) conducted the study and collected the data. All authors (JN, HC, GC, YJ, $F Y, Z Z, Y Y, J$. Wu, XC, BS, J. Wang, YL, DG, XQ, XL, YW, JD, HL, Yining $H$, Yonghua $\mathrm{H}, \mathrm{BX}, \mathrm{TG}$, and $L C$ ) approve of the submitted version of the manuscript and agree to be held accountable for the accuracy and integrity of any part of the work.

\section{Funding}

This study was sponsored by Peking Sihuan Pharmaceutical Company. Peking Sihuan Pharmaceutical Company had no role in the design and execution of the study, the development of the manuscript, or the decision to publish.

\section{Availability of data and materials}

The datasets used and/or analyzed during the current study are available from the corresponding author on reasonable request.

\section{Ethics approval and consent to participate}

This study was conducted in accordance with the ethical guidelines for human medical research as stated in the Declaration of Helsinki (2013). In addition, this study was conducted in accordance with the ethical principles of the Chinese Good Clinical Practice for Drug Administration. All patients provided voluntary written informed consent prior to commencing any study procedures. The ethics committees of all 72 research institutes reviewed and approved the study protocol (see Table 4 in Appendix 1 for committee names and reference numbers).

\section{Consent for publication}

Not applicable.

\section{Competing interests}

Yong $\mathrm{Ji}$ is an Associate Editor and an editorial board member of BMC Neurology. All other authors (J. Ni, H. Chen, G. Chen, F. Yi, Z. Zhang, Y. Yang, J. Wu, X. Cai, B. Shao, J. Wang, Y. Liu, D. Geng, X. Qu, X. Li, Y. Wei, J. Ding, H. Lü, Y. Huang, Y. Huang, B. Xiao, T. Gong, L. Cui) declare that they have no competing interests.

\section{Author details}

${ }^{1}$ Peking Union Medical College Hospital, Chinese Academy of Medical Sciences, No.1 Shuaifuyuan Wangfujing Dongcheng District, Beijing 100730, China. ${ }^{2}$ General Hospital of Northern Theater Command, Shenyang, China. ${ }^{3}$ Xuzhou Central Hospital, Xuzhou, China. ${ }^{4}$ Tianjin Huanhu Hospital, Tianjin, China. ${ }^{5}$ Pingxiang People's Hospital, Pingxiang, China. ${ }^{6}$ Fourth Affiliated Hospital of Harbin Medical University, Harbin, China. ${ }^{7}$ First Bethune Hospital of Jilin University, Changchun, China. ${ }^{8}$ Second Affiliated Hospital of Nanjing Medical University, Nanjing, China. ${ }^{9}$ Lishui Municipal Central Hospital, Lishui, China. ${ }^{10}$ First Affiliated Hospital of Wenzhou Medical University, Wenzhou, China. ${ }^{11}$ Dalian Municipal Central Hospital, Dalian, China. ${ }^{12}$ Huangshi Central Hospital, Huangshi, China. ${ }^{13}$ Affiliated Hospital of Xuzhou Medical University, Xuzhou, China. ${ }^{14}$ Jiangxi Provincial People's Hospital affiliated to Nanchang University, Nanchang, China. ${ }^{15}$ Jinan Central Hospital, Jinan, China. ${ }^{16}$ Hengshui People's Hospital (Harrison International Peace Hospital), Hengshui, China. ${ }^{17}$ Xuan Wu Hospital, Capital Medical University, Beijing, China. ${ }^{18}$ Shaanxi Provincial People's Hospital, Xi'an, China. ${ }^{19}$ Peking University First Hospital, Beijing, China. ${ }^{20}$ Seventh Medical Center of the Chinese PLA General Hospital, Beijing, China. ${ }^{21}$ Xiangya Hospital Central South University, Changsha, China. ${ }^{22}$ Beijing Hospital, Beijing, China. 
Received: 14 February 2020 Accepted: 26 June 2020

Published online: 14 July 2020

\section{References}

1. Global Burden of Disease Collaborative Network. Global Burden of Disease Study 2017 (GBD 2017). Results. 2018; http://ghdx.healthdata.org/gbdresults-tool. Accessed 11 Nov 2019.

2. Wang W, Jiang B, Sun H, Ru X, Sun D, Wang L, et al. Prevalence, incidence, and mortality of stroke in China: results from a nationwide populationbased survey of 480687 adults. Circulation. 2017;135:759-71.

3. Adams HP, Bendixen BH, Kappelle L, Biller J, Love BB, Gordon DL, et al. Classification of subtype of acute ischemic stroke. Definitions for use in a multicenter clinical trial. TOAST. Trial of org 10172 in acute stroke treatment. Stroke. 1993;24:35-41.

4. Musuka TD, Wilton SB, Traboulsi M, Hill MD. Diagnosis and management of acute ischemic stroke: speed is critical. CMAJ. 2015;187:887-93.

5. Hacke W, Kaste M, Bluhmki E, Brozman M, Dávalos A, Guidetti D, et al. Thrombolysis with alteplase 3 to 4.5 hours after acute ischemic stroke. N Engl J Med. 2008;359:1317-29.

6. Fugate JE, Rabinstein AA. Absolute and relative contraindications to IV rt-PA for acute ischemic stroke. Neurohospitalist. 2015;5:110-21.

7. Zhu Y, Zhang G, Zhao J, Li D, Yan X, Liu J, et al. Efficacy and safety of mildronate for acute ischemic stroke: a randomized, double-blind, activecontrolled phase II multicenter trial. Clin Drug Invest. 2013;33:755-60.

8. Hirohashi M, Hagihara Y. Effect of 1-[(1-pyrrolidynylcarbonyl) methyl]-4-(3, 4, 5-trimethoxycinnamoyl) piperazine maleate (cinepazide) on cerebral and peripheral circulation in cats. Nihon Yakurigaku Zasshi. 1979;75:495-506 [Article in Japanese].

9. Moritoki H, Takei M, Fujita S, Ishida Y, Akashi A. Interaction of cinepazide with adenosine on Guinea-pig atria. Arch Int Pharmacodyn. 1980;248:212-24.

10. Muramatsu I, Sakakibara Y, Hong SC, Fujiwara M. Effects of cinepazide on the purinergic responses in the dog cerebral artery. Pharmacology. 1984;28: $27-33$.

11. Liu Y, Luo Z, Sun A, Ye L, Gao L, Zhang Z, et al. Dynamic changes of adenosine content and neuron-specific enolase protein expression after focal cerebral ischemic reperfusion injury in rats. Chin J Clin Rehabil. 2004;8: 1863-5.

12. Zhang W, Li J, Wei A. Clinical effectiveness and safety of Kelinao in the treatment of ischemic stroke. New Concepts Clin Neurol. 2005;44:195-7.

13. Liu B, et al. Therapeutic effects of cinepazide maleate in craniocerebral injured patients. Chin J Neurosurg. 2006;11:663-5.

14. Zhang W, et al. Efficacy of cinepazide maleate in treatment of patients with acute carotid system stroke. Chin J Geriatr Cardiovasc Dis. 2009;11:781-3.

15. Yi Z, Liu F, Di S. Cinepazide maleate injection for cerebral infarction: a systematic review. Chin J Evid Based Med. 2010;9:1079-84.

16. Chinese Neurology Association, Stroke Committee. Guideline of diagnosis and treatment in acute ischemic stroke 2014. Chi J Neuro. 2015:48:246-57.

17. Adams HP Jr, Davis PH, Leira EC, Chang KC, Bendixen BH, Clarke WR, et al. Baseline $\mathrm{NIH}$ stroke scale score strongly predicts outcome after stroke: a report of the trial of org 10172 in acute stroke treatment (TOAST). Neurology. 1999;53:126-31.

18. European Medicines Agency. ICH Topic E9, Statistical Principles for Clinical Trials: ICH Harmonised Tripartite Guideline; 1998. https://www.ema.europa. eu/en/documents/scientific-guideline/ich-e-9-statistical-principles-clinicaltrials-step-5_en.pdf. Accessed 11 Nov 2019.

19. Food and Drug Administration. Adaptive designs for clinical trials of drugs and biologics: guidance for industry. 2018. https://www.fda.gov/media/784 95/download. Accessed 11 Nov 2019.

20. Zhang T, Zhao X, Tian S. Efficacy of cinepazide maleate in treatment of patients with acute carotid system stroke. Chin I Geriatr Heart Brain Vessel Dis. 2009;11:781-3.

21. Ongini E, Adami M, Ferri C, Bertorelli R. Adenosine A2A receptors and neuroprotection. Ann N York Acad Sci. 1997;825:30-48.

22. Kitagawa H, Mori A, Shimada J, Mitsumoto Y, Kikuchi T. Intracerebral adenosine infusion improves neurological outcome after transient focal ischemia in rats. Neurol Res. 2002;24:317-23.

23. Pedata F, Pugliese AM, Coppi E, Popoli P, Morelli M, Schwarzschild MA, et al. Adenosine in the central nervous system: effects on neurotransmission and neuroprotection. Immunol Endocr Metab Agents Med Chem. 2007;7:304-21.
24. Fredholm BB, Chen J, Masino SA, Vaugeois J. Actions of adenosine at its receptors in the CNS: insights from knockouts and drugs. Ann Rev Pharmacol Toxicol. 2005;45:385-412.

25. Bruckner UB, Schmidt J. Effects of cinepazide, a new vasoactive substance, on canine coronary circulation after acute constriction of the left anterior descending coronary artery. Arzneimittelforschung. 1976;26:1569-74.

26. Akashi A, Hirohashi M, Suzuki I, Shibamura S, Kasahara A. Cardiovascular pharmacology of cinepazide, a new cerebral vasodilator. Nihon Yakurigaku Zasshi. 1979;75:507-16 [In Japanese].

27. Taylor-Rowan M, Wilson A, Dawson J, Quinn TJ. Functional assessment for acute stroke trials: properties, analysis, and application. Front Neurol. 2018;9:191.

28. Ma L, Jia L, Daihong G. Analysis of adverse reactions report of 10830 cases of cinepazide maleate. 10,830 cases cinepazide maleate drug association analysis of adverse reaction reports. J Pharma Epidemiol. 2017;03:183 [in Chinese].

29. Guo D, Wang X, Liu J, Zhang X, Zhang M, Yong X, et al. Automatic monitoring and evaluation of cinepazide maleate related ADR in 19487 hospitalized patients of five hospitals. Chin J Drug Appl Monit. 2017;14:221-4.

30. Hu P, Wang X, Guo D, Ma L, Fan Q, Liu J, Xia Y, Tian X. Automatic monitoring of liver and kidney damage in 11665 patients with cinepazide maleate. Chin J Drug Appl Monit. 2017:14:99.

31. Guo D, Hu P, Wang X, Liu J, Xia Y, Ma L, Fan Q, Tian X. Automated monitoring of adverse reactions in blood system of 11665 patients with cinepazide maleate. Chin J Clin Pharmacol. 2017;33:1484-7.

32. Hacke W, Donnan G, Fieschi C, Kaste M, von Kummer R, Broderick JP, et al. Association of outcome with early stroke treatment: pooled analysis of ATLANTIS, ECASS, and NINDS rt-PA stroke trials. Lancet. 2004;363:768-74.

\section{Publisher's Note}

Springer Nature remains neutral with regard to jurisdictional claims in published maps and institutional affiliations.

\section{Ready to submit your research? Choose BMC and benefit from:}

- fast, convenient online submission

- thorough peer review by experienced researchers in your field

- rapid publication on acceptance

- support for research data, including large and complex data types

- gold Open Access which fosters wider collaboration and increased citations

- maximum visibility for your research: over $100 \mathrm{M}$ website views per year

At BMC, research is always in progress.

Learn more biomedcentral.com/submissions 